\title{
Surviving in uncertainty: experiences of recession in Knocknaheeny, Cork
}

\author{
Sander van Lanen \\ Department of Geography, UCC
}

The larger context of economic insecurity and cultural uncertainty in which young working-class men and women come of age is restructuring the kinds of adults they are growing into. (Jennifer M. Silva)

\section{Introduction}

Memories of being sent home from a construction site, parents who suddenly struggle to make ends meet, moving back into ones parental home, but also the feeling that nothing has really changed at all. These are some of the experiences young adults in Knocknaheeny have of the 2007 financial crash and the following recession. Knocknaheeny is an area described as deprived, with more than one in four unemployed, while $40 \%$ of those employed are semi- or unskilled and about a third of the population has finished primary education only. A neighbourhood were some parts benefited from the property boom of the 2000s while others are third generation unemployed. It is the neighbourhood in which the first part of my research on the experiences of recession by disadvantaged urban youth takes place.

I am not the first to write about austerity, increasing uncertainty and impacts of the recession on different aspects of life in Ireland. Both academic and non-academic publications have dealt with these issues massively, and the crisis and its aftermath is still an almost daily topic in newspapers. Most of the attention, though, focusses on relatively well of segments of society; university students that can't find a 'real job' and have to take on unpaid internships, skilled workers who can only guarantee temporary contracts and college graduates working call centres and coffee shops. But what about those for whom stable employment maybe never was on the horizon? Low skilled workers were the first to be laid off, those dependent on social welfare feel the cuts in spending directly and those without further education now have to compete for semi-skilled jobs with those who went to college. It is their experiences I am interested in, and it is for this reason that I selected Knocknaheeny in Cork and Ballymun in Dublin as my research sites.

\section{Phenomenology}

To investigate the impacts of the recession on the everyday life of young urban adults I use a phenomenological approach. Alan Bryman describes phenomenology as "a philosophy 
that is concerned with the question of how individuals make sense of the world around them". It recognises that social reality has meaning for people, and that this meaning guides their behaviour. It is from this recognition that it aims to interpret people's actions and their social world from their perspective. The phenomenological interview gathers description of a participant's lifeworld relating to the interpretation and meaning of a certain phenomenon, which is crisis and recession in this research. These personal experiences and meaning that the participant allocate to the phenomenon are at the heart of the interview and the aim is to understand the meaning of crisis and recession within the reality of the participant, to see how the world appears to the interviewee. The main focus is on the relation between the participant and the theme of research, and the participant's experience of the recession.

In total I conduct in between 15 and 20 interviews with young adults, aged between 18 and 25, from Knocknaheeny, Cork. Interviews start with general questions about the participants' experience of recession and when and how they felt its impacts, and if and how this changed their behaviour and experiences in everyday life. After this, I use follow up questions to get information on all the topics I am interested in. To make sure the information stays as close to the personal experience as possible I use the language used by the participant. This ensures that they use vocabulary they are most familiar with, and creates an atmosphere in which the participant feels confident to share their story. I make sure I talk to them afterwards and ask how they felt about the interview, to receive feedback, reflect on my practice and improve interviews to come.

Interviews are not the only method used, they will be followed up by 'walking tours' with some of the participants. Here they will show me around their neighbourhood while we have a conversation about the impacts of the recession on their everyday lives. Through this method it is possible to better ground these experiences in space while it also allows me to observe how participants interact with their surroundings and others living in the area. Not everyone agrees to participate in this, but sometimes even this rejection leads to valuable information, as a 20 year old woman told me she would like to, but cannot as she almost always has to babysit the various children in her extended family after work.

\section{The lifeworld}

Limiting the influence of the recession to the labour market and the financial situation of people would deny the totality of its impacts. Although these are the most straight forward and direct ways in which people are affected, increased insecurity related to a loss of income and more precarious working conditions permeate into almost every aspect of people's everyday life. It is for this reason that I deploy the concept of the lifeworld, described by Anne Buttimer as "the cultural defined spatio-temporal setting or horizon of everyday life". It is the lifeworld that contains the choices and options one has in everyday life, and it is defined by the complex interactions of time, material conditions and cultural 
values and expectations. Increased insecurity in several parts of one's live can severely impact ones lifeworld, and it is these changes I am looking for.

The lifeworld imposed by external factors can have clear physical boundaries. For example, a 24 year old male from Knocknaheeny described how he could not visit his family as often as he wanted.

"My dad lives down in Douglas as well, so my little sister again, she's only four, and I don't get enough time to see them at all. I'm living too far away. My other sister lives down in Cobh and I never get to see her. I never get to see my sister down in Fermoy, never ever get to see my brother up in Dublin. It's all money, they don't have money, I don't have money, so, that's kind of hard, like."

Here financial and spatial factors combine and prevent him from visiting his brother and sisters, who, he expressed elsewhere in our interview, are very important to him. Family comes up as important in almost all of the interviews, a lot of people want to get employment to be able to help out 'at home'. Most of the people I interviewed donate towards family expenses even when on a very low allowance themselves.

A 26 year old man told me he lives in a homeless hostel by choice, but that choice is once again structured by external factors. He is unable to afford accommodation in Cork City, and is aware that he would be able to afford a house outside of the city, but as he does not own a car he would be unable to access the casual jobs that he works every now and then. Here the interplay of transport possibilities, labour market accessibility and housing shape the horizon of this man's actions and decisions.

The impacts of the recession also overflow into people's social world, as their limited movement in time and space, due to limited financial means and options, prevents seeing friends in ways people used to. Above it was already mentioned how one participant can no longer see his family as much as he wanted, a 20 year old women told me she regularly lies to her friends that she doesn't want to go to the cinema, because she hates it when they offer to pay for her tickets.

"It's hard, because you can't really do anything anymore, like, you used to be able to do fun things with your friends, like go shopping, and cinemas and that, but you can't anymore."

But the lifeworld is not only a limiting factor, it is also the areas in which relations develop. Although sometimes caused by an inability to move out, many of the participants have most of their friends and families live within walkable distance from their house. Having lived in the area for most of their lives, people have a dense network of contacts within the area. Almost every participant talks about help and support coming from these networks, varying from babysitting each other's children, sharing rides to work and town, and helping each other out if necessary. 


\section{What about the future?}

For my research I work with people aged 18 to 25 years old, focussing on those that (tried) to enter the labour market after the start of the recession. Since I work with young adults, the future is an important aspect of our conversations. As became clear in many of the interviews, the recession not only caused an increasingly insecure present, but it multiplies when it comes to plans and expectations for the future. As another 24 year old male expressed "Before you can start thinking of those things [a girlfriend and a family], you got to have stability in your life". He was not the only one who expressed that he felt stuck, that he could not make the development he wished for, as another one said:

"My parents, they told me when they were younger they were out living by themselves at 18 , starting families at $22 / 23$, and here I am, 24, still at home, doing the same thing, just different day."

It is the absence of stability, of a regular income, that makes it impossible for these young adults to move out of their parental home, to start a family, to make plans for the future. This makes some of them feel like their future is put on hold, they are not developing, but always waiting for something to happen and move on.

Since this is a generation that comes of age in an era of austerity and precariousness, it shapes what kind of adults they become. Through the study of the changing lifeworld of disadvantaged urban youth I will shed light on how insecurity gets embedded in relations formed within these individual's communities, and how it impacts their relation to their neighbourhood and the state. Understanding how coming of age after the crash influences individuals helps to think about the kind of policies and support that might be necessary for those at the receiving end of austerity, and how current policies shape the Irish society of the future.

In the near future I will complement my interviews in Knocknaheeny with another form of data gathering. This will take the form of a walking tour, where participants show me around their neighbourhood while having a conversation about the impacts of crisis and austerity on their everyday lives. This allows me to clearly ground their stories in space, while observing how they interact with their environment. I will also perform interviews and walking tours in Ballymun, Dublin, to get a clearer understanding of the recession's impact in Irish cities, and look for similarities and differences between disadvantaged areas within Cork and Dublin. After analysing and comparing the different methodologies and cities I can give a clearer answer to how the recession changes the lifeworld of young urban adults. Investigating changes in lifeworld, individually and communally, provides insight in how marginalized and vulnerable populations experience life in times of crises. In this way this investigation will contribute to an understanding of austerity's impact on everyday life, the spatial, social and cultural effects of increased insecurity, and the way in which neoliberalism gets embedded and/or contested in everyday lived experiences. By providing a finer understanding on the direct and indirect effects of austerity and crisis 
politics the outcomes of this work can provide valuable information for support organisations and community groups, and inform policy makers trying to alleviate concentrated poverty and deprivation. However the research will be used, one thing is certain: the future is unsure.

I would like to thank my supervisors Dr. Denis Linehan and Dr. Therese Kenna for their feedback and support. I would also like to acknowledge the Department of Geography, UCC, for the funding received for this project. 